\title{
COMPARAÇÃO DE MÉTODOS DE RUPTURA CELULAR E EXTRAÇÃO DE LIPÍDIOS DE BIOMASSA PERIFÍTICA
}

\author{
DAHMER, M. N. ${ }^{1}$; ALTMEYER, J. A ${ }^{1}$; SOUZA, M. P. ${ }^{2}$; ZIEMANN, F. ${ }^{3}$; SCHNEIDER, R. C. S4, RIZZETTI, T. Mㄴ, \\ BENITEZ, L. B $^{6}$.
}

PALAVRAS-CHAVE: PERIFITON, DISRUPÇÃO CELULAR, LIPÍDIOS.

\begin{abstract}
RESUMO
O perifíton é uma comunidade complexa de organismos aquáticos aderidos a substratos submersos, dentre os quais destacam-se as microalgas, cujo conteúdo em lipídios reflete essa diversidade. Este estudo buscou desenvolver um método utilizando a irradiação por micro-ondas para rompimento da parede celular das microalgas, visando a extração dos lipídios com maior eficiência que o método tradicional de Bligh e Dyer. Partindo do planejamento fatorial $2^{3}$, as amostras foram secas a $50^{\circ} \mathrm{C}$ até peso constante, irradiadas por microondas $\left(65^{\circ} \mathrm{C}\right.$ e $\left.200 \mathrm{~W}\right)$, centrifugadas, filtradas e secas a $70^{\circ} \mathrm{C}$ até peso constante. 0 maior rendimento lipídico foi no experimento $7(6,27 \%)$, utilizando tempo de extração maior (15 minutos), menor quantidade de biomassa (300 mg) e maior proporção de metanol (2:1). Pelo método de Bligh e Dyer, o maior rendimento foi de 9,17\%, porém foram gastos $7 \mathrm{~mL}$ de clorofórmio, $1 \mathrm{~mL}$ de metanol e 5 horas e 50 minutos a mais. As condições de extração alteraram o perfil de ácidos graxos obtidos, já que, com a tecnologia de ultrassom foram obtidos mais dois ácidos graxos (C:12 e C18:0 n-6 isômero) da biomassa. A análise das superfícies de resposta das variáveis avaliadas revelou que o tempo de extração de 15 minutos, o emprego de $300 \mathrm{mg}$ de biomassa e a proporção de metanol/clorofórmio (2:1) promovem a obtenção de um rendimento de lipídios extraídos maior a partir da biomassa empregada neste estudo. Concluiu-se que, a disrupção celular por micro-ondas é uma alternativa viável, pois envolve menores tempos de processamento, mão-de-obra e gastos com solventes.
\end{abstract}

\section{COMPARISON OF CELL DISRUPTION METHODS AND PERIPHYTIC BIOMASS LIPID EXTRACTION}

\author{
KEYWORDS: PERIPHYTON, CELL DISRUPTION, LIPIDS.
}

\begin{abstract}
Periphyton is a complex community of aquatic organisms adhered to submerged substrates, among which stand out as microalgae, whose lipid content reflects this diversity. This study sought to develop a method using microwave irradiation to disrupt the cell wall of microalgae, the extraction of lipids with greater efficiency than the traditional method of Bligh and Dyer. Based on factorial planning 23, how they were dried at $50{ }^{\circ} \mathrm{C}$ to constant weight, irradiated by microwaves $\left(65^{\circ} \mathrm{C}\right.$ and $\left.200 \mathrm{~W}\right)$, centrifuged, filtered and dried at $70^{\circ} \mathrm{C}$ until constant weight. The highest lipid yield was in experiment 7 (6.27\%), using longer extraction time (15 minutes), less biomass (300 mg) and higher proportion of methanol (2: 1). By the method of Bligh and Dyer, the highest yield was $9.17 \%$, but $7 \mathrm{~mL}$ of chloroform, $1 \mathrm{~mL}$ of methanol and 5 hours and 50 minutes more were spent. The modified extraction conditions of the fatty acid profile obtained, since, with the ultrasound technology, two more fatty acids (C: 12 and C18: 0 n-6 isomer) of the biomass were chosen. The analysis of the response surfaces of the evaluated variables revealed that the extraction time of 15 minutes, the use of $300 \mathrm{mg}$ of biomass and the proportion of methanol /

\footnotetext{
1 Acadêmicos do Curso de Engenharia Química, Universidade de Santa Cruz do Sul. E-mails: mainarand@mx2.unisc.br, joaoantonio1986@hotmail.com

2 Doutoranda do Programa de Pós-Graduação em Tecnologia Ambiental, Universidade de Santa Cruz do Sul.

${ }^{3}$ Acadêmico do Curso de Farmácia, Universidade de Santa Cruz do Sul.

${ }^{4}$ Professora Doutora do Programa de Pós-Graduação em Tecnologia Ambiental, Universidade de Santa Cruz do Sul. E-mail: rosana@unisc.br

5 Pós-doutoranda do Programa de Pós-Graduação em Tecnologia Ambiental, Universidade de Santa Cruz do Sul

${ }^{6}$ Professora Doutora do Programa de Pós-Graduação em Tecnologia Ambiental, Universidade de Santa Cruz do Sul E-mail: lisianne@unisc.br.
} 
chloroform (2:1) promote the result of a higher yield of extracted lipids from the biomass used in this study. It was concluded that, a microwave cell disruption is a viable alternative, as it involves shorter processing times, labor and expenses with solvents.

\section{INTRODUÇÃO}

As comunidades perifíticas são biofilmes complexos formados por multiespécies fototróficas que se desenvolvem em superfícies de ambientes aquáticos. Essas comunidades abrigam uma grande diversidade de organismos, incluindo algas, microalgas, bactérias, fungos, metazoários, vírus e protozoários (SANLI et al., 2015). As microalgas, presentes no perifíton, são capazes de realizar fotossíntese e se reproduzirem em taxas relativamente altas produzindo substâncias de elevado potencial de exploração comercial, assim, têm despertado o interesse dos pesquisadores e vêm sendo amplamente estudadas (PULZ \& GROSS 2004; MARTINI et al., 2019).

Dentre as moléculas extraídas de micro-organismos, como as microalgas por exemplo, é possível observar o aumento do interesse nos lipídios. Isto acontece devido à importância dos micro-organismos nas diversas cadeias tróficas e na possibilidade da aplicação destes lipídios em diferentes áreas como nutrição, saúde humana e animal, tratamento de águas residuais, produção de energia e obtenção de compostos de interesse das indústrias alimentícia, química e farmacêutica, dentre outras (RICHMOND, 2004).

0 processo de extração de lipídios de células microalgais difere das culturas alimentares tradicionais, na medida em que as paredes celulares das células de microalgas devem ser rompidas para liberar os compostos lipídicos, antes da extração propriamente dita. No entanto, a estrutura robusta da parede celular das microalgas limita a taxa de ruptura celular quando se utilizam métodos mecânicos normais, inibindo a dissolução dos lipídios e, consequentemente dificultando a extração lipídica (YU-AN et al., 2014).

Desta forma a ruptura da parede celular das microalgas passa a representar a etapa chave na extração e recuperação de lipídios, de tal forma que a seleção dos solventes apropriados se torna fundamental para o processo de extração, uma vez que compromete a estrutura desta parede celular assegurando a sua ruptura e, por conseguinte, a extração de lipídios (ARAÚJO et al., 2013).

0 tratamento com ultrassom altera as estruturas celulares microbianas por dois mecanismos principais: a cavitação, seguida da propagação das ondas de choque. 0 último fenômeno forma fluxos de jatos no meio circundante, causando assim a ruptura celular por forças de cisalhamento de alta resistência (GERDE et al., 2012; GUNERKEN et al., 2015). 0 tratamento com micro-ondas, por sua vez, é um método no qual não há o contato direto com a amostra, sendo todos os reagentes alvos aquecidos simultaneamente. As principais vantagens do tratamento com irradiação por micro-ondas são o curto tempo de processamento, a alta eficiência de disrupção e um consumo de energia relativamente baixo (CHENG et al., 2013).

Este estudo teve por objetivo principal desenvolver um método que utiliza a irradiação por micro-ondas como uma forma de facilitar a ruptura da parede celular das microalgas presentes na biomassa residual de um perifíton, obtida em um sistema Algae Turf Scrubber (ATS), visando extrair os lipídios presentes com maior eficiência que o método tradicional de Bligh e Dyer (1959). A irradiação por micro-ondas envolve um tempo de processamento, mão-de-obra e gastos com solventes muito menores. 
0 artigo está organizado nas seguintes seções: a seção 2 apresenta a fundamentação teórica que aborda assuntos relacionados com perifíton, microalgas, lipídios e seus diferentes métodos de extração. A seção 3 traz os materiais e métodos utilizados para a extração dos lipídios da microalga. A seção 4 apresenta os resultados desta extração, por meio da análise dos dados obtidos. Na seção 5 contém a conclusão da pesquisa, que avalia o desempenho dos métodos de extração.

\section{FUNDAMENTAÇÃO TEÓRICA}

Esta seção apresenta os assuntos relacionados à pesquisa desenvolvida para extração de lipídios em perifítons por meio de diferentes métodos como, Bligh e Dyer e micro-ondas.

\subsection{Perifíton}

O perifíton, também conhecido como biofilme, é um microecossistema composto por uma matriz complexa de mucopolissacarídeos com micro-organismos autotróficos e heterotróficos incorporados e possui a capacidade natural de responder e se recuperar do estresse (SABATER et al., 2007). A comunidade perifítica é composta por algas bentônicas fotoautotróficas, diatomáceas, bactérias, fungos, protozoários, zooplâncton, vírus e invertebrados menores (AZIM e ASAEDA, 2005; LARNED, 2010).

\subsection{Microalgas do perifíton}

As microalgas estão presentes principalmente nos ambientes aquáticos, sendo este grupo de microorganismos denominados de fitoplâncton e classificados como produtores primários de energia, representando a base da cadeia alimentar em ecossistemas aquáticos. Destacam-se por apresentarem uma elevada eficácia na captura e incorporação do $\mathrm{CO}_{2}$ atmosférico, pois possuem uma alta eficiência fotossintética, além de uma taxa de proliferação rápida, ampla adaptabilidade de tolerância a ambientes extremos e excelente desenvolvimento em cultivos intensivos (ANDRADE; FILHO, 2014).

0 estudo das microalgas tem recebido uma relevância considerável devido à variedade de aplicações que podem ter, dentre as quais destacam-se os processos de biorremediação e a síntese de bioprodutos de alto valor. A biomassa de microalgas é conhecida pela composição rica e variada em lipídios, carboidratos, proteínas, pigmentos e antioxidantes, os quais podem ser usados para inúmeros propósitos, como por exemplo, produção de biocombustíveis, nutrição alimentar (humana e animal), farmacologia e cosmetologia (DE SOUZA et al., 2018).

São componentes de um grupo muito variado de organismos e seus lipídios refletem essa diversidade, apresentando teores de lipídios totais que variam de acordo com a espécie, os níveis de nutrientes, o tipo de cultivo utilizado na produção da biomassa e as condições experimentais nas quais foram avaliadas (CHISTI, 2007; KHAN et al., 2009; MATA; MARTINS; CAETANO, 2010).

\subsubsection{Conteúdo lipídico das microalgas}

Os lipídios extraídos da biomassa de algas foram recentemente identificados como matéria-prima potencial para a produção de biodiesel (KUMAR, SINGH, 2019). Os ácidos graxos normalmente encontrados nas microalgas variam em comprimento de cadeia, grau de insaturação e posição na molécula de glicerol. 
Consequentemente, a própria fração de triglicerídeos consiste em uma mistura complexa de diferentes tipos de moléculas (Ríos et al., 2013).

As células das microalgas tendem a produzir lipídios em maior quantidade quando são submetidas a condições de cultivo sob estresse, isto é, em condições de escassez de nitrogênio, que revertem o metabolismo de carboidratos e proteínas para lipídios (SURENDHIRAN et al., 2015).

0 estresse por nitrogênio geralmente apresenta efeitos desproporcionais sobre o crescimento e o teor de lipídios, com uma grande diferença entre as microalgas neste sentido, sendo necessário um intervalo amplo entre as espécies no que diz respeito à taxa de fornecimento de nitrogênio para a cultura. Isto, com intuito de produzir uma biomassa com um alto teor de lipídios, a partir de organismos que combinam a capacidade de acumular lipídios em resposta ao estresse mínimo de nitrogênio em concomitância com o seu crescimento. Desse modo, o cultivo em batelada se mostra mais eficaz do que os sistemas de cultivo semicontínuos com relação à otimização do crescimento e as compensações do conteúdo lipídico, mesmo para espécies que requerem um menor estresse de nitrogênio (ADAMS et al., 2013).

Da mesma forma, a composição bioquímica pode variar consideravelmente em função da concentração de dióxido de carbono no meio ou até mesmo devido à espécie de microalga empregada como, por exemplo, em processos de mitigação de dióxido de carbono em fotobiorreatores, nos quais determinadas espécies (Chlorella sp., Scenedesmus sp. e Spirulina platensis) produzem mais proteínas ou lipídios, em condições de cultivo igualitárias com relação aos níveis de $\mathrm{CO}_{2}$ (SINGH et al., 2016). Neste contexto, concentrações elevadas de dióxido de carbono também podem influenciar de forma diferente nos perfis de crescimento das microalgas sendo este fator associado às características de tolerância e adaptabilidade de cada espécie durante o processo de cultivo (KASSIM; MENG, 2017).

Outras abordagens para a induzir a produção de lipídios pelas microalgas incluem temperatura, estresse de salinidade, intensidade de luz, dióxido de carbono e a influência de metais. Na prática, as estratégias de indução podem ser combinadas em um esforço para alcançar a otimização na síntese de lipídios por estes microorganismos (ZHU; LI; HILTUNEN, 2016).

\subsection{Métodos de extração de lipídios de microalgas}

0 princípio de extração de lipídios de microalgas por solventes apolares orgânicos está embasado no conceito da química básica de polaridade: "semelhante dissolve semelhante". Quando a microalga é exposta a um solvente orgânico neutro, como hexano ou clorofórmio, o solvente penetra através da parede celular no citoplasma e interage com os lipídios neutros através de forças de van der Walls para formar um complexo solvente-lipídio. Esse complexo orgânico solvente-lipídio é conduzido por um gradiente de concentração disperso através da parede celular e de um filme orgânico que envolve a célula. Consequentemente, os lipídios neutros são extraídos para fora da célula, permanecendo dissolvidos no solvente orgânico apolar (ANDRADE; FILHO, 2014).

Ren et al. (2017) obtiveram êxito em promover um incremento da ruptura do material celular da microalga Chlorella protothecoides, e consequentemente o aumento da liberação de lipídios intracelulares, ao adicionar uma etapa de tratamento com água entre a primeira e segunda etapa de extração com solventes, de quatros métodos clássicos de extração de lipídios, sem alterar a composição dos ácidos graxos extraídos. Segundo os autores deste estudo, ao ressuspender as células com água entre as etapas citadas acima, ocorreria 
um aumento da polaridade da mistura de solventes nas extremidades das células, aumentando assim a eficácia da segunda fase de extração em todos os métodos avaliados.

Huang e Kim (2016) desenvolveram uma abordagem simples, eficiente e rápida para e ruptura simultâneas de células de microalgas através do tratamento das mesmas com nanopartículas de óxido de níquel, atingindo uma eficiência na extração de 98,75\% após 1 minuto da adição das nanopartículas a pH 7 e uma elevada eficiência na extração dos lipídios depois de 96 horas de contato da biomassa com as nanopartículas de $\mathrm{NiO}$, demonstrando o potencial deste tipo de material para extração de lipídios de microalgas sem a necessidade do emprego de solventes orgânicos.

Segundo Araújo et al. (2013) a etapa chave na extração e recuperação de lipídios de microalgas é a ruptura celular, de tal forma que a seleção dos solventes apropriados é fundamental para o processo de extração, uma vez que compromete a estrutura da parede celular assegurando a sua ruptura e, por conseguinte, a extração de lipídios. Dependendo do pré-tratamento aplicado na concentração de células da biomassa de microalgas, esta pode ser submetida à extração de lipídio na forma concentrada úmida ou em pó seco (ANDRADE; FILHO, 2014).

Lorenzen et al. (2017) otimizaram um processo de extração de lipídios de microalgas por dióxido de carbono supercrítico. Tais frações lipídicas geradas das microalgas por este procedimento cumpriam todas as qualificações para serem empregadas como matéria-prima para formulações de produtos finais, particularmente em aplicações como biolubrificantes e nutracêuticos. Da mesma forma que a inserção de etapas de tratamento com radiação por micro-ondas foi capaz de ampliar a capacidade de extração de lipídios de microalgas de diferentes métodos de extração avaliados (TEO; IDRIS, 2014).

Olmstead et al. (2013) desenvolveram um método para extração de lipídios da biomassa de microalgas utilizando hexano em baixas proporções de solvente e biomassa, a baixa temperatura $\left(35^{\circ} \mathrm{C}\right)$. A utilização de hexano permitiu a recuperação preferencial dos lipídios neutros adequados para a produção de biodiesel e evitou dificuldades associadas à recuperação de solventes polares. 0 uso de processos de choque osmótico e ultrassom para a extração de lipídios e proteínas, a partir da microalga Spirulina platensis, foi testado por Hadiyanto e Adetya (2018) com resultados considerados promissores, especialmente devido a uma maior velocidade de extração destes compostos a partir dos métodos citados.

No estudo de Martini et al. (2019), a partir de uma biomassa perifítica obtida do mesmo sistema ATS deste estudo, também foi utilizado o método de Bligh \& Dyer para determinação dos lipídios totais e o ultrassom para a ruptura celular das microalgas presentes. Apesar de terem obtido como resultado baixos teores de lipídios consideraram positiva a presença de uma elevada concentração de ácidos graxos insaturados essenciais.

Outra alternativa para extração de lipídios de microalgas é a utilização de radiação ultrassônica, a qual representa um passo importante no desenvolvimento de novas tecnologias de extração sustentável com tempo e solventes reduzidos (JAESCHKE et al., 2017). 0 uso de ultrassom favorece a ruptura celular e aumenta o rendimento de lipídios extraídos tornando mais eficientes os métodos de extração que utilizam solventes orgânicos como o clorofórmio e o metanol (DOS SANTOS et al., 2015).

\subsubsection{Bligh e Dyer}

0 método de extração desenvolvido por Bligh e Dyer (1959) encontra aceitação geral como procedimento padrão para recuperação de lipídios totais, sendo este método dependente de clorofórmio e metanol, para formar 
um sistema de solventes monofásicos, com o intuito de extrair e dissolver os lipídios. Um sistema bifásico é então produzido em um passo de purificação pela adição de água, levando à separação de compostos polares e não polares em uma fase superior (aquosa) e inferior (orgânica) respectivamente (AXELSSON; GENTILI, 2014). Este método pode ser empregado para a extração de lipídios de qualquer tipo de tecido contendo até $80 \%$ de água (IVERSON; LANG; COOPER, 2011).

A adição de cloreto de potássio no passo de separação pode modificar a distribuição de lipídios entre as duas fases e às vezes é considerada como uma substância que favorece a troca lipídica entre a fase aquosa e a fase orgânica. Supõe-se que este fenômeno ocorra devido à geração de cátions pelos sais (cloreto de potássio) que diminuíram a dissociação de lipídios por um efeito de ação em massa, que, portanto, deslocam os mesmos para a fase orgânica, mantendo os sais na fase aquosa (BREIL et al., 2017).

A utilização de uma mistura de metanol e clorofórmio (1:1) como solventes para extração de lipídios é a mais adequada devido ao seu custo reduzido e maior rendimento lipídico em comparação com, por exemplo, o n-hexano (LEE et al., 2010).

\subsubsection{Irradiação por micro-ondas}

As micro-ondas revelam características de aquecimento uniforme e rápido, pouco consumo de solventes e curto tempo de extração (ENCINAR; GONZÁLEZ; REINARES, 2007). Esta tecnologia gera ondas de alta frequência, que destroem as células por meio da indução de choque, tornando este, um método eficiente para a disrupção das células de plantas contendo óleo (AMARO; GUEDES; MALCATA, 2011). Assim este passo de tratamento com disrupção celular pode ter um impacto sobre a extratibilidade e o rendimento lipídico de microalgas (RANJAN; PATIL; MOHOLKAR, 2010).

\subsection{Sistema Algae Turf Scrubber}

o Algal Turf Scrubber (ATS) é um ecossistema controlado para o tratamento de águas residuais através do escoamento de efluentes sobre uma superfície inclinada que é coberta por um biofilme de perifíton (LIU et al., 2016). Este sistema representa uma tecnologia especialmente promissora que pode integrar com sucesso a fitorremediação com a geração de biomassa para propósitos de biocombustíveis (ADEY et al., 2011). Além disso, a biomassa derivada do ATS é fácil de separar da água tratada, sem aplicar processos de desidratação caros e que consomem energia, como a centrifugação ou a filtragem sob pressão (LIU et al., 2016).

\section{MATERIAIS E MÉTODOS}

Nesta seção apresenta os assuntos relacionados aos materiais e métodos utilizados na extração de lipídios da biomassa perifítica estudada nesta pesquisa.

\subsection{Biomassa empregada}

A biomassa perifítica empregada neste estudo foi proveniente de um sistema de biorremediação (Algal Turf Scrubber), localizado às margens do Lago Dourado, no município de Santa Cruz do Sul, Rio Grande do Sul. As amostras utilizadas foram previamente secas em estufa, a uma temperatura de $50{ }^{\circ} \mathrm{C}$ até peso constante. 


\subsection{Otimização dos ensaios de extração de lipídios com disrupção celular por micro-ondas}

A fim de se incrementar a ruptura celular da biomassa periifítica, empregando o método de irradiação por micro-ondas, os parâmetros quantidade de biomassa, tempos de extração e proporção de metanol e clorofórmio foram otimizados a partir de um planejamento experimental fatorial $2^{3}$ (FILHO, 2017). Os níveis das variáveis utilizadas no processo de extração podem ser observados na Tabela 1.

Tabela 1 -Especificação dos níveis das variáveis empregadas no processo de extração.

\begin{tabular}{ccc}
\hline Variáveis & Níveis & +1 \\
\hline Biomassa (mg) & -1 & 500 \\
Tempo (min) & 300 & 15 \\
Proporção de Metanol/Clorofórmio & 5 & $1: 2$ \\
\hline
\end{tabular}

Cada um dos oito experimentos, gerados no planejamento fatorial, foi realizado em triplicata e a determinação dos rendimentos em lipídios ocorreu segundo a equação:

$$
R=\frac{(F 2-F 1) \cdot 100}{m}
$$

Onde:

$\mathbf{R}=$ rendimento de lipídios totais extraídos (em \% de biomassa seca);

F1 = massa do balão de fundo redondo vazio $(\mathrm{mg})$;

F2 = massa do balão de fundo redondo + lipídios totais $(\mathrm{mg})$;

$\mathrm{m}=$ massa da amostra de biomassa seca $(\mathrm{mg})$.

Na etapa de disrupção celular foi empregado um equipamento de micro-ondas (CEM, Discover System) a uma temperatura de $65^{\circ} \mathrm{C}$ e uma potência de $200 \mathrm{~W}$. Após o transcorrer dos respectivos tempos de exposição à irradiação por micro-ondas, as amostras foram centrifugadas (3600 rpm) por 10 minutos, sendo as fases aquosas removidas, com a posterior filtração das fases orgânicas com o auxílio de papéis filtros. As amostras filtradas foram secas em estufa a $70{ }^{\circ} \mathrm{C}$ até peso constante, por aproximadamente $24 \mathrm{~h}$.

\subsection{Bligh e Dyer adaptado com disrupção celular por ultrassom}

Inicialmente pesou-se $0,3 \mathrm{~g}$ da biomassa em um tubo cônico ao qual foram adicionados $6 \mathrm{~mL} \mathrm{de} \mathrm{CHCl}_{3}$ e $3 \mathrm{~mL}$ de MeOH. Este tubo cônico passou então por um processo de disrupção por ultrassom, com banho de gelo, durante 45 minutos, permanecendo em repouso por 4 horas sobre refrigeração (método original preconiza um tempo de refrigeração de 12 horas). Posteriormente o processo de sonicação por 30 minutos foi repetido, seguido de uma etapa de centrifugação a 3600 rpm por 10 minutos. A fase lipídica foi separada em outro recipiente, sendo adicionado à biomassa residual $1 \mathrm{~mL}$ de $\mathrm{CHCl}_{3}$ e $2 \mathrm{~mL}$ de $\mathrm{MeOH}$. Este tubo cônico contendo a biomassa residual passou novamente por processos de sonicação e centrifugação, respectivamente, ambos por 15 minutos. A fase lipídica foi separada, sendo incorporada à fase orgânica removida anteriormente. A este recipiente contendo o somatório das fases lipídicas foram adicionados $4 \mathrm{~mL}$ de $\mathrm{H}_{2} \mathrm{O}$ ultrapura e $2 \mathrm{~mL}$ de $\mathrm{CHCl}_{3}$, passando o mesmo, em seguida, por uma etapa de centrifugação por 10 minutos. Após o processo de centrifugação, transferiu-se a fase lipídica para um balão de fundo redondo, o qual foi seco em estufa a $50{ }^{\circ} \mathrm{C}$ até peso constante. 
O método de Bligh e Dyer (1959) adaptado com disrupção celular por ultrassom foi realizado em triplicata para determinação do rendimento de lipídios extraídos, sendo este utilizado como referência na comparação com a técnica de disrupção celular com micro-ondas, desenvolvido neste estudo.

\subsection{Derivatização}

As derivatizações das amostras de lipídios extraídos pelos métodos de Bligh e Dyer (1959) adaptado e pelo método desenvolvido neste projeto foram realizadas conforme os métodos da AOCS modificado por Gressler (2011) e adaptado para as condições do presente estudo.

Para a realização da técnica de derivatização foram empregadas as amostras de lipídios, contidas nos balões de fundo redondo de $25 \mathrm{~mL}$, utilizados para a determinação dos rendimentos das frações lipídicas extraídas, sendo transferidos os conteúdos dos três balões para um único balão de fundo redondo de $50 \mathrm{~mL}$ com o auxílio de $6 \mathrm{~mL}$ de uma solução metanólica (hidróxido de sódio e metanol na proporção de 1:50).

Em seguida efetuou-se o aquecimento dos mesmos em sistemas de refluxo durante 20 minutos. Após este tempo adicionou-se $7 \mathrm{~mL}$ de uma solução de trifluoreto de boro-metanol $\left(\mathrm{BF}_{3} / \mathrm{metanol}\right)$, gota a gota, através dos condensadores destes sistemas, deixando em refluxo por mais 4 minutos. Na sequência, foram adicionados, via condensadores, $5 \mathrm{~mL}$ de heptano, e as amostras foram deixadas em refluxo por mais 2 minutos.

Passado este tempo, os balões foram retirados dos sistemas de refluxo e deixados esfriar até alcançarem a temperatura ambiente, para que então ocorresse a transferência dos produtos do processo de derivatização para tubos de ensaio, aos quais foram adicionados $2 \mathrm{~mL}$ de uma solução saturada de $\mathrm{NaCl}$. Coletou-se, em seguida, a fase superior de cada uma das amostras contidas nos tubos de ensaio, transferindo-as para frascos de vidro. A estes frascos de vidro foi adicionada uma ponta de espátula de sulfato de sódio anidro, previamente ativado em estufa a $100^{\circ} \mathrm{C}$, durante uma hora. Por último $500 \mu \mathrm{L}$ de cada um dos extratos obtidos foram diluídos com $500 \mu \mathrm{L}$ de n-hexano em vials para posterior análise cromatográfica.

\subsection{Identificação dos ácidos graxos}

As análises para identificação dos ésteres metílicos de ácidos graxos presentes nos lipídios extraídos foram realizadas em um cromatógrafo gasoso equipado com Injetor Automático A0C5000. As amostras derivatizadas foram analisadas por Cromatografia Gasosa Acoplada à Espectrometria de Massa pelo método AOCS (Ce 1c-89), modificado por AOCS (2008). As condições de aquecimento da coluna ZB-WAX (30 m x 0,25 $\mathrm{mm} \times 0,25 \mu \mathrm{m})$ foram de $70^{\circ} \mathrm{C}(0,1 \mathrm{~min})$ aquecendo até $240^{\circ} \mathrm{C}\left(4^{\circ} \mathrm{C} \mathrm{min}-1\right)$, permanecendo o aquecimento por 5 minutos e depois por mais 5 minutos a $250^{\circ} \mathrm{C}$. No detector de massas a temperatura da fonte de ionização e a temperatura de interface foram de $260^{\circ} \mathrm{C}$. 0 sistema de injeção foi utilizado no modo split (1:10) a $250^{\circ} \mathrm{C}$ e o detector de massas foi mantido no modo scan. A mistura de padrões e amostras foi injetada em duplicata em alíquotas de $1 \mu \mathrm{L}$ para identificação dos ésteres metílicos presentes. Estimaram-se a partir das áreas de cada um dos picos nos cromatogramas, as porcentagens de cada ácido graxo presente nos extratos analisadas, sendo necessário para isso, excluir os demais picos que não representavam quaisquer ácidos graxos.

\subsection{Análise dos dados}


A análise dos rendimentos de lipídios extraídos pelos métodos empregados neste estudo foi realizada no programa Microsoft Excel ${ }^{\circledR}$ 2010, para a determinação das médias dos rendimentos de lipídios extraídos, bem como dos seus respectivos desvios padrões e coeficientes de variação.

Os principais efeitos entre as variáveis em estudo foram determinados por meio do teste t-Student, considerando os efeitos estatisticamente significativos quando $p<0,05$, e de gráficos de superfície de resposta, ambos empregando o software Chemoface (versão 1.5).

\section{RESULTADOS E DISCUSSÃo}

Nesta seção apresenta os resultados relacionados aos métodos de extração de lipídios, bem como a comparação do perfil lipídico e a análise de efeitos.

\subsection{Comparação dos métodos de extração de lipídios}

Ao empregar-se a disrupção celular por irradiação com micro-ondas foi possível observar um rendimento maior de lipídios extraídos no experimento 7 (6,27 \%), em comparação com os demais ensaios realizados. Além disso, foi possível observar melhor resposta, em termos de rendimento lipídico, nos experimentos que empregaram um tempo de extração maior (15 minutos), uma quantidade menor de biomassa (300 mg) e uma proporção maior de metanol (Tabela 2). Uma hipótese para a obtenção de melhores resultados com a utilização de uma quantidade menor de biomassa poderia ser o fato desta, quando testada em maior quantidade, ter comprometido o sistema de agitação do equipamento de micro-ondas, diminuindo a superfície de contato dos solventes com a mesma, e consequentemente reduzindo a eficácia do processo de extração dos lipídios.

A variação do conteúdo lipídico extraído, presente nas microalgas, tende a variar de acordo com a espécie, os níveis de nutrientes e o tipo de cultivo utilizado na produção da biomassa (CHISTI, 2007; KHAN et al., 2009; MATA; MARTINS; CAETANO, 2010).

Tabela 2 - Experimentos de extração de lipídios realizados pelos métodos de Bligh e Dyer adaptado e com irradiação por micro-ondas, com seus respectivos rendimentos, desvios padrão e coeficientes de variação.

\begin{tabular}{|c|c|c|c|c|c|c|c|}
\hline $\begin{array}{l}\text { Método de } \\
\text { ruptura } \\
\text { celular }\end{array}$ & Experimento & $\begin{array}{c}\text { Biomassa } \\
(\mathrm{mg})\end{array}$ & $\begin{array}{c}\text { Tempo de } \\
\text { irradiação } \\
\text { (min) }\end{array}$ & $\begin{array}{c}\text { Proporção } \\
\mathrm{MeOH} / \mathrm{CHCl}_{3} \\
(\mathrm{~mL})\end{array}$ & $\begin{array}{l}\text { Média de } \\
\text { rendimento } \\
(\%), n=3\end{array}$ & $\begin{array}{l}\text { Desvio } \\
\text { Padrão } \\
\text { (DP\%) }\end{array}$ & $\begin{array}{l}\text { Coeficiente } \\
\text { de Variação } \\
\text { (CV\%) }\end{array}$ \\
\hline \multirow{8}{*}{$\begin{array}{c}\text { Irradiação } \\
\text { por } \\
\text { micro- } \\
\text { ondas }\end{array}$} & 1 & 300 & 5 & $1: 2$ & 5,66 & 0,55 & 9,75 \\
\hline & 2 & 500 & 5 & $1: 2$ & 1,59 & 0,53 & 33,14 \\
\hline & 3 & 300 & 5 & $2: 1$ & 5,35 & 0,68 & 12,64 \\
\hline & 4 & 500 & 5 & $2: 1$ & 4,53 & 0,19 & 4,25 \\
\hline & 5 & 300 & 15 & $1: 2$ & 4,29 & 1,21 & 28,18 \\
\hline & 6 & 500 & 15 & $1: 2$ & 5,28 & 1,59 & 30,16 \\
\hline & 7 & 300 & 15 & $2: 1$ & 6,27 & 0,93 & 14,89 \\
\hline & 8 & 500 & 15 & $2: 1$ & 3,42 & 0,44 & 12,78 \\
\hline Ultrassom & 1 & 300 & - & 1:2 & 9,17 & 0,24 & 2,63 \\
\hline
\end{tabular}


0 experimento realizado pelo método de Bligh e Dyer adaptado com etapas de ruptura celular por ultrassom apresentou um rendimento maior de lipídios extraídos (9,17\%) em comparação com o experimento 7 , apresentado na Tabela 2. Porém, para alcançar tal resultado, foram gastos $7 \mathrm{~mL}$ de clorofórmio, $1 \mathrm{~mL}$ de $\mathrm{metanol}$ e um tempo de 5 horas e 50 minutos a mais do que no experimento 7.

Este tempo excessivo destinado aos procedimentos de extração de lipídios de microalgas por métodos convencionais, como o Bligh e Dyer adaptado, representa uma limitação deste tipo de técnica, o que dificulta o processamento de um grande número de amostras (RAWAT et al., 2013).

\subsection{Comparação do perfil lipídico entre os métodos de extração}

$\mathrm{Na}$ análise do extrato obtido pela tecnologia de ultrassom foi possível observar a presença de outros dois ácidos graxos (C:12 e C18:0 $\omega$-6 isômero) na amostra de biomassa perifítica em estudo (Tabela 3), quando comparado com o método por micro-ondas. Segundo Halim et al. (2011) a alteração das condições de extração altera o perfil dos ácidos graxos obtidos, o que explicaria os diferentes resultados encontrados em nosso estudo, a partir dos métodos de extração empregados.

A análise da estimativa percentual de cada ácido graxo presente nos extratos avaliados, demostrou haver uma variação nas suas quantidades, em todos os experimentos. 0 ácido palmítico foi o ácido graxo que se apresentou em maior quantidade em todos os ensaios com irradiação por micro-ondas, bem como no método de Bligh e Dyer adaptado (Tabela 3). Segundo Carta et al. (2015), o ácido palmítico é o ácido graxo mais comum encontrado no corpo humano, representando $20-30 \%$ dos ácidos graxos totais em fosfolipídios de membrana e triacilglicerois do tecido adiposo, sendo responsável por exercer múltiplas funções biológicas fundamentais, nos níveis celular e tecidual. Considerando estas propriedades, existe a possibilidade de utilização dos óleos provenientes desta biomassa para a produção de suplementos alimentares.

A irradiação por micro-ondas produz um baixo percentual de ésteres metílicos com mais de 19 carbonos em comparação com métodos convencionais de extração, o que permite a obtenção de um biodiesel de baixa viscosidade e, portanto, um produto de boa qualidade (TEO E IDRIS, 2014). Os ácidos araquídico (C20:0) e behênico (C22:0) estavam presentes em percentuais baixos, em todos os experimentos de extração com disrupção por irradiação de micro-ondas, indicando a possibilidade de utilização dos óleos obtidos neste estudo, por meio do emprego desta tecnologia, para a produção de biodiesel.

Tabela 3 - Perfil de ácidos graxos obtidos a partir dos extratos provenientes dos experimentos de extração de lipídios realizados, com suas respectivas estimativas de porcentagem para cada ácido graxo.

\begin{tabular}{|c|c|c|c|c|c|c|c|c|c|c|}
\hline $\begin{array}{l}\text { Ácidos } \\
\text { graxos }\end{array}$ & Simbologia & $\begin{array}{c}\text { Ex:1 } \\
R(\%)\end{array}$ & $\begin{array}{c}\text { Ex:2 } \\
R(\%)\end{array}$ & $\begin{array}{c}\text { Ex:3 } \\
R(\%)\end{array}$ & $\begin{array}{c}\text { Ex:4 } \\
R(\%)\end{array}$ & $\begin{array}{c}\text { Ex:5 } \\
R(\%)\end{array}$ & $\begin{array}{c}\text { Ex:6 } \\
R(\%)\end{array}$ & $\begin{array}{c}\text { Ex:7 } \\
R(\%)\end{array}$ & $\begin{array}{c}\text { Ex:8 } \\
R(\%)\end{array}$ & $\begin{array}{l}B \text { e } D \\
R(\%)\end{array}$ \\
\hline Láurico & C:12 & - & - & - & - & - & - & - & - & 5,39 \\
\hline Mirístico & C14:0 & 11,22 & 12.32 & 10,68 & 10,54 & 7,52 & 10,37 & 9,89 & 11,27 & 12,68 \\
\hline Pentadecílico & C15:0 & 2,05 & 1,97 & 1,98 & 2,37 & 1,98 & 2,10 & 1,94 & 2,57 & 1,43 \\
\hline Palmítico & C16:0 & 41,47 & 45,31 & 40,34 & 37,52 & 59,65 & 37,71 & 38,32 & 40,24 & 33,56 \\
\hline Palmitoleico & $c 16: 1 \omega-7$ & 6,42 & 0,19 & 6,09 & 6,62 & 0,19 & 6,08 & 5,80 & 6,91 & 3,54 \\
\hline Margárico & C17:0 & 0,94 & 0,90 & 0,91 & 1,2 & 2,57 & 0,89 & 0,66 & 1,33 & 1,63 \\
\hline$\alpha$-Linolênico* & C18:3 $\omega-3$ & 2,27 & 2,27 & 2,64 & 2,54 & 5,84 & 2,98 & 2,79 & 0,44 & 3,37 \\
\hline Esteárico & C18:0 & 9,96 & 10,46 & 9,78 & 10,50 & 11,34 & 9,58 & 9,35 & 11,95 & 14,17 \\
\hline Oleico & C18:1 $\omega-9$ & 14,43 & 15,22 & 14,89 & 13,93 & 6,44 & 14,33 & 14,67 & 6,23 & 3,81 \\
\hline Linoleico* & C18:2 $\omega-6$ & - & - & - & - & - & - & - & - & 7,28 \\
\hline
\end{tabular}




\begin{tabular}{|c|c|c|c|c|c|c|c|c|c|c|}
\hline$\alpha$-Linolênico & C18:3 $\omega-3$ & 7,72 & 7,73 & 8,72 & 7,59 & 0,10 & 9,95 & 8,99 & 10,29 & 7,98 \\
\hline Araquídico & C20:0 & 0,80 & 0,80 & 0,83 & 1,09 & 0,86 & 0,79 & 0,81 & 1,15 & 0,80 \\
\hline Araquidônico & $C 20: 4 \omega-6$ & 4,06 & 4,25 & 4,74 & 4,81 & 1,51 & 7,39 & 5,86 & 6,36 & 1,07 \\
\hline Behênico & C22:0 & 0,92 & 0,86 & 1,03 & 1,27 & 2,00 & 0,81 & 0,91 & 1,27 & 3,30 \\
\hline
\end{tabular}

* = isômero

$R=$ rendimento de lipídios extraídos da biomassa em estudo

Ex $=$ experimento

$B$ e $D=$ Bligh e Dyer adaptado

\subsection{Análise dos efeitos}

0 Gráfico de Pareto, representado na Figura 1, demonstra os efeitos entre as interações das variáveis empregadas e de forma isolada, sobre o rendimento de lipídios extraídos pelo método de extração com disrupção celular por irradiação de micro-ondas.

As interações entre as variáveis biomassa e solvente, biomassa e tempo, tempo e solvente, bem como a variável tempo de forma isolada, apresentaram efeitos estatisticamente significativos sobre o rendimento de lipídios extraídos, com nível de confiança de 95\%.

Figura 1 - Gráfico de Pareto obtido pelo planejamento experimental.

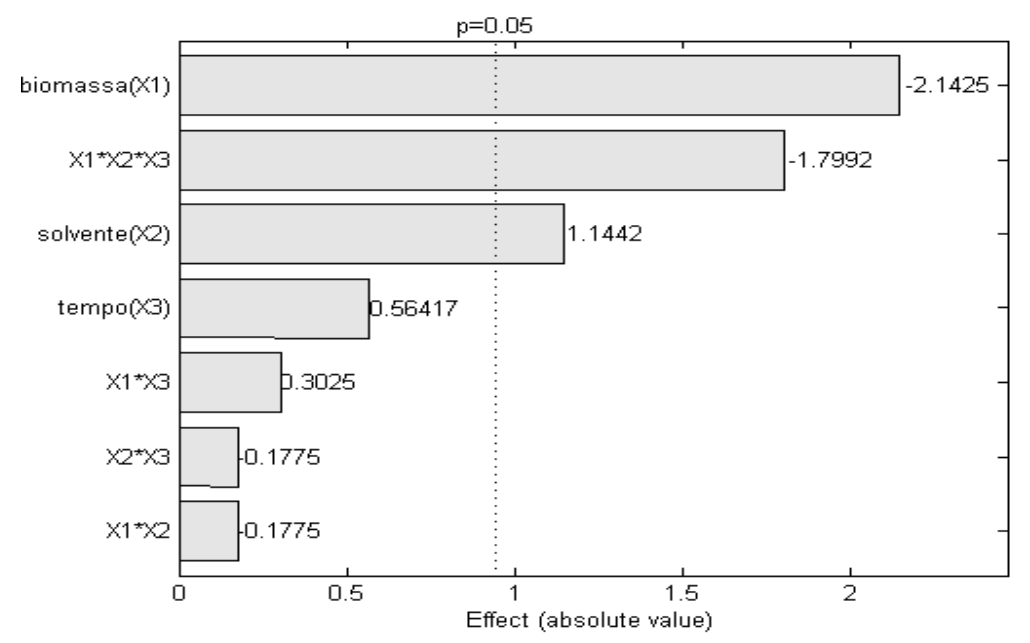

O efeito das interações entre a quantidade de biomassa, proporção dos solventes e o tempo de extração sobre o rendimento de lipídios extraídos pelo método de extração com irradiação por micro-ondas são demostrados na forma de gráficos de superfície de resposta (Fig.2). Foi possível observar uma melhor resposta, com relação ao rendimento de lipídios extraídos, nos experimentos que empregaram um tempo de extração maior (15 minutos), uma quantidade menor de biomassa (300 mg) e uma proporção maior de metanol. Uma hipótese para a obtenção de melhores resultados com a utilização de uma quantidade menor de biomassa poderia ser o fato desta, quando em maior quantidade, comprometer o sistema de agitação do equipamento de micro-ondas, diminuindo a superfície de contato dos solventes com a mesma, e consequentemente reduzindo a eficácia do processo de extração dos lipídios. Este mesmo fenômeno foi observado por Axelsson e Gentili. (2014), quando ao comparar diferentes métodos de extração de lipídios de microalgas com a inserção de irradiação por microondas, incluindo o método de Bligh e Dyer, observaram uma redução dos rendimentos de lipídios extraídos, 
a medida em que eram empregadas quantidade maiores de biomassa de microalgas. Os mesmos realizaram uma análise para determinação do limite de tamanho da amostra, para um sistema de extração por solventes, com um volume máximo de $10 \mathrm{~mL}$ (semelhante ao volume máximo do micro-ondas empregado em nosso estudo), a qual revelou que os mesmos poderiam extrair até $300 \mathrm{mg}$ e $90 \mathrm{mg}$ de biomassa úmida e seca, respectivamente, por vez, sem prejudicar o rendimento de lipídios extraídos. Um tempo maior de extração (20 min) foi associado a um rendimento maior de lipídios extraídos (3,8\%) no estudo realizado por Drira et al. (2016), os quais também empregaram uma variação do método de Bligh e Dyer, com a inserção de irradiação por microondas, testando tempos de extração de 5 e 20 minutos. Smedes e Askland (1999), por sua vez, testaram várias proporções de clorofórmio e metanol, descritas pelo método de Bligh e Dyer, e sugeriram que o rendimento de lípidos poderia ser aumentado usando um teor maior de metanol, assim como ocorreu em nosso estudo.

Figura 2 - Gráficos de superfície de resposta sobre os efeitos das interações entre (a) o tempo de extração e proporção dos solventes; (b) proporção dos solventes e quantidade de biomassa; (c) tempo de extração e quantidade de biomassa sobre a porcentagem de lipídios extraídos pelo método de extração com irradiação por micro-ondas.

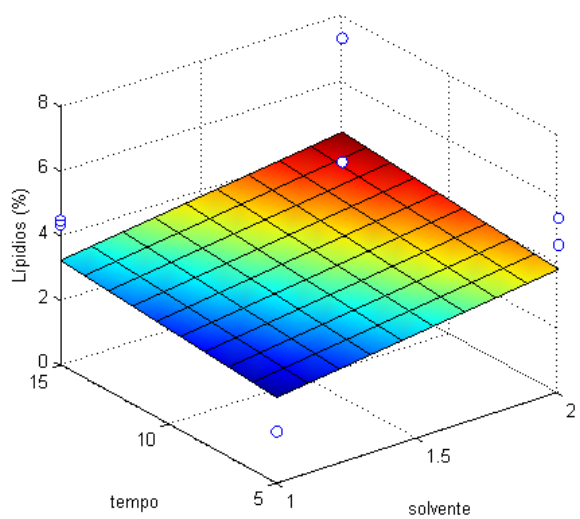

(a)

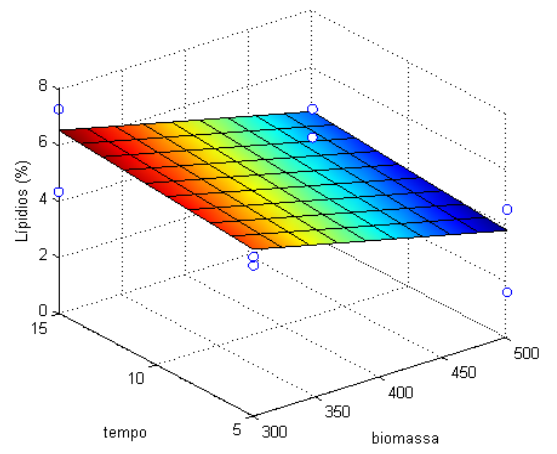

(c)

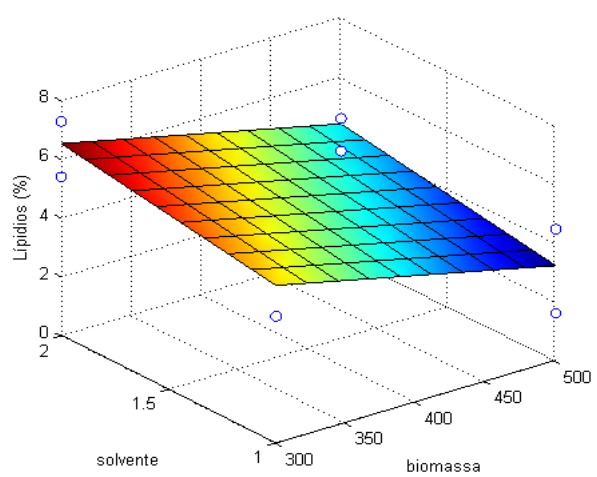

(b) 


\section{CONCLUSÃo}

Foi possível desenvolver uma técnica de disrupção celular com irradiação de micro-ondas, como forma de incrementar a extração de lipídios, com um desempenho satisfatório, comparado ao método de Bligh e Dyer adaptado empregando a disrupção por ultrassom, reduzindo tempo de extração e quantidade de solventes empregados. Com relação ao perfil de ácidos graxos, o mesmo permaneceu qualitativamente inalterado em todos os experimentos, nos quais foi utilizada a irradiação por micro-ondas. Porém, este perfil lipídico mostrou-se diferente no método de extração de Bligh e Dyer adaptado com etapas ruptura celular por sonicação, devido ao surgimento de outros dois ácidos graxos (C:12 e C18:0 $\omega$-6 isômero). Na análise dos efeitos de resposta das diferentes variáveis empregadas no método de irradiação por micro-ondas foi possível observar que os resultados mais satisfatórios foram obtidos utilizando um tempo de extração e uma proporção de metanol maiores, em concomitância com uma quantidade menor de biomassa.

Portanto, a extração de lipídios com a disrupção celular por micro-ondas pode vir a ser empregada como uma alternativa vantajosa para substituir os métodos que utilizam a sonicação, devido à economia de tempo, mão-de-obra e menores gastos com solventes.

\section{AGRADECIMENTOS}

Os autores agradecem ao CNPq pelo apoio financeiro, à Universidade de Santa Cruz do Sul, ao Programa de Pós-Graduação Mestrado e Doutorado em Tecnologia Ambiental e ao Parque Tecnológico UNISC (TecnoUNISC).

\section{REFERÊNCIAS}

ADAMS, C. et al. Understanding precision nitrogen stress to optimize the growth and lipid content tradeoff in oleaginous green microalgae. Bioresource Technology, v. 131, p. 188-194, 2013.

ADEY, W.H. et al. Algal turf scrubbing: cleaning surface waters with solar energy while producing a biofuel. Bioscience, v. 61, p. 434-441, 2011.

AMARO, H. M; GUEDES, A. C.; MALCATA, F. X. Advances and perspectives in using microalgae to produce biodiesel. Applied Energy, v. 88, n. 10, p. 3402-3410, 2011.

ANDRADE, D. S.; FILHO, A. C. Microalgas de águas continentais: Potencialidades e desafios do cultivo. Londrina: lapar, 2014.

ARAÚJO, G. S. et al. Extraction of lipids from microalgae by ultrasound application: Prospection of the optimal extraction method. Ultrasonics Sonochemistry, v. 20, n. 1, p. 95-98, 2013.

AXELSSON, M.; GENTILI, F. A single-step method for rapid extraction of total lipids from green microalgae. Plos One, v. 9, n. 2, p. e89643, 2014.

AZIM, M.E., ASAEDA, T., 2005. Periphyton structure, diversity and colonization. In: Azim, M.E., Beveridge, M.C.M., van Dam, A.A. (Eds.), Periphyton: Ecology, Exploitation and Management. CABI Publishing, pp. 15e49.

BREIL, C. et al. "Bligh and Dyer" and folch methods for solid-liquid-liquid extraction of lipids from microorganisms. Comprehension of solvatation mechanisms and towards substitution with alternative solvents. International Journal of Molecular Sciences, v. 18, p. 708, 2017. 
CARTA, G., MURRU, E., LISAI, S., SIRIGU, A., PIRAS, A., COLLU, M., 2015. Dietary triacylglycerols with palmitic acid in the sn-2 position modulate levels of N-acylethanolamides in rat tissues. PLoS ONE, (10), e0120424. Disponível em: 10.1371/journal.pone.0120424 Acessado em: 28 jun. 2019.

CHENG, J., SUN, J., HUANG, Y., FENG, J., ZHOU, J., CEN, K., 2013. Dynamic microstructures and fractal characterization of cell wall disruption for microwave irradiation-assisted lipid extraction from wet microalgae. Bioresource Technology, 150, 67-72. Disponível em: 10.1016/j.biortech.2013.09.126 Acessado em: 20 jun. 2019.

CHISTI, Y. Biodiesel from microalgae. Biotechnology Advances, v. 25, n. 3, p. 294-306, 2007.

DOS SANTOS, R. R. et al. Comparison between several methods of total lipid extraction from Chlorella vulgaris biomass. Ultrasonics Sonochemistry, v. 22, p. 95-99, 2015.

DRIRA, N, PIRAS A., ROSA, A., PORCEDDA, S., DHAOUADI, H. Microalgae from domestic wastewater facility's high rate algal pond: Lipids extraction, characterization and biodiesel production. Bioresource.Technology, 206, 239-244, 2016.

ENCINAR, J. M.; GONZÁLEZ, J. F.; REINARES, A. R. Ethanolysis of used frying oil. Biodiesel preparation and characterization, Fuel Processing Technology, v. 88, p. 513-522, 2007.

GERDE, J. A., MONTALBO-LOMBOY, M., YAO, L., GREWELL, D., WANG, T., 2012. Evaluation of microalgae cell disruption by ultrasonic treatment. Bioresource Technology, 125, 175-181. Disponível em: 10.1016/j.biortech.2012.08.110 Acessado em: 15 jun. 2019.

GUNERKEN, E., D'HONDT, E., EPPINK, M.H.M., GARCIA-GONZALEZ, L., ELST, K., WIJFFELS, R.H., 2015. Cell disruption for microalgae biorefineries. Biotechnology Advances, 33, 243-260. Disponível em: 10.1016/j.biotechadv.2015.01.008_Acessado em: 2 jul. 2019.

HADIYANTO, H.; ADETYA, N.P. Response surface optimization of lipid and protein extractions from Spirulina platensis using ultrasound assisted osmotic shock method, Food Science Biotechnology, 25(5): 1361-1368. 2018.

HALIM, R., GLADMAN, B., DANQUAH, M.K., WEBLEY, P.A., 2011. Oil extraction from microalgae for biodiesel production. Bioresource Technology, 102 (1), 178-85. Disponível em: 10.1016/j.biortech.2010.06.136 Acessado em: 28 jun. 2019.

HUANG, W. C.; KIM, J. D. Nickel oxide nanoparticle-based method for simultaneous harvesting and disruption of microalgal cells. Bioresource Technology, v. 218, p. 1290-1293, 2016.

IVERSON, S. J.; LANG, S. L.; COOPER, M. H. Comparision of the Bligh and Dyer and Folch methods for total lipid determination in a broad range of marine tissue. Lipids, v. 36, n. 11, p. 1283-1290, 2011.

JAESCHKE, D. P. et al. Ultrasound as an alternative technology to extract carotenoids and lipids from Heterochlorella luteoviridis. Bioresource Technology, v. 224, p. 753-757, 2017.

KASSIM, M. A.; MENG, T. K. Carbon dioxide $\left(\mathrm{CO}_{2}\right)$ biofixation by microalgae and its potential for biorefinery and biofuel production. Science of The Total Environment, v. 584, p. 1121-1129, 2017.

KHAN, S. A. et al. Prospects of biodiesel production from microalgae in India. Renewable and Sustainable Energy Reviews, v. 13, n. 9, p. 2361-2372, 2009.

LARNED, S.T. A prospectus for periphyton: recent and future ecological research. J. N. Am. Benthol. Soc. 29(1):182-206, 2010.

LEE, J.Y. et al. Comparison of several methods for effective lipid extraction from microalgae. Bioresource Technology, v. 101, p. 575-577, 2010. 
LIU et al. Nutrient removal from horticultural wastewater by benthic filamentous algae Klebsormidium sp., Stigeoclonium spp. and their communities: From laboratory flask to outdoor Algal Turf Scrubber (ATS). Water Research, 2016.

LORENZEN, J. et al. Extraction of microalgae derived lipids with supercritical carbon dioxide in an industrial relevant pilot plant. Bioprocess and Biosystems Engineering, p. 1-8, 2017.

MARTINI, F.A., RUBERT, A., DE SOUZA, M.P. et al. Periphytic biomass composition and exploitation from algae turf scrubber system. SN Appl. Sci. 1, 765 (2019). https://doi.org/10.1007/s42452-019-0802-z. Acessado em: 28 jun. 2019.

MATA, T. M.; MARTINS, A. A.; CAETANO, N. S. Microalgae for biodiesel production and other applications: a review. Renewable and Sustainable Energy Reviews, v. 14, n. 1, p. 217-232, 2010.

OLMSTEAD, I. L. D. et al. Low solvent, low temperature method for extracting biodiesel lipids from concentrated microalgal biomass. Bioresource Technology, v. 148, p. 615-619, 2013.

PULZ, O.; GROSS, W. Valuable products from biotechnology of microalgae. Applied Microbiology Biotechnology, v.65, p.635-648, 2004

RANJAN, A.; PATIL, C.; MOHOLKAR, V.S. Mechanistic assessment of microalgal lipid extraction. Industrial and Engineering Chemistry Research, v. 49, n. 6, p. 2979-2985, 2010.

RAWAT, R. et al. Biodiesel from microalgae: A critical evaluation from laboratory to large scale production. Applied Energy, v. 103, p. 444-467, 2013.

REN, $X$. et al. Current lipid extraction methods are significantly enhanced adding a water treatment step in Chlorella protothecoides. Microbial Cell Factories, v. 16, n. 1, p. 26, 2017.

RICHMOND, A. Handbook of microalgal culture:biotechnology and applied phycology. Oxford: Blackwell Science, 2004.

RíOS, S. B. et al. Lipid extraction methods from microalgal biomass harvested by two different paths: Screening studies toward biodiesel production. Bioresource Technology, v. 133, p. 378-388, 2013.

SABATER, S., GUASCH, H., RICART, M., ROMANI, A., VIDAL, G., KLUNDER, C., SCHMITT-JANSEN, M., 2007. Monitoring the effect of chemicals on biological communities. The biofilm as an interface. Analytical and Bioanalytical Chemistry 387 (4), $1425 \mathrm{e} 1434$.

SANLI, K. et al. Metagenomic sequencing of marine periphyton: taxonomic and functional insight Sint biofilm communities. Frontiers in Microbiology, v. 6, p. 1-14, 2015.

SINGH, S. K. et al. Evaluation of promising algal strains for sustainable exploitation coupled with $\mathrm{CO}_{2}$ fixation. Environmental Technology, v. 37, n. 5, p. 613-622, 2016.

SMEDES, F., ASKLAND, T. K., Revisiting the development of the Bligh and Dyer total lipid determination. Mar. Poll. Bull. (38), 193-201, 1999.

SURENDHIRAN, D. et al. Kinetic modeling of microalgal growth and lipid synthesis for biodiesel production. 3 Biotech, v. 5, n. 5, p. 663-669, 2015.

TEO, C. L.; IDRIS, A. Enhancing the various solvent extraction method via microwave irradiation for extraction of lipids from marine microalgae in biodiesel production. Bioresource Technology, v. 171, p. 477-481, 2014.

YU-AN, M. et al. Effects of ultrasonic and microwave pretreatments on lipid extraction of microalgae. Bioprocess and Biosystems Engineering, v. 37, n. 8, p. 1543-1552, 2014.

ZHU, L. D.; LI, Z. H.; HILTUNEN, E. Strategies for lipid production improvement in microalgae as a biodiesel feedstock. BioMed Research International, v. 2016, 2016. 
